\title{
UM BREVE RELATO SOBRE O ATELIÊ FIDALGA E O PROJETO FIDALGA
}

ABRIEF ACCOUNT ABOUT ATELIÊ FIDALGA AND THE FIDALGA PROJECT

Sandra Cinto

Ateliê Fidalga

Albano Afonso

Ateliê Fidalga

Resumo: Os artistas Sandra Cinto e Albano Afonso relatam sobre a transformação do grupo de estudos do Ateliê Fidalga, em que assumiam o papel de mediar o diálogo e fomentar trocas num processo horizontal de aprendizado mútuo em arte, para o Projeto Fidalga, composto de 4 ateliês coletivos, três salas expositivas, e um programa de residência artística com o objetivo de abrigar exposições experimentais e trabalhos desenvolvidos pelos artistas residentes e artistas convidados.

Palavras-Chave: Arte; Ateliê Fidalga; Projeto Fidalga; Residência Artística; Colaboração entre artistas.

Abstract: The artists Sandra Cinto and Albano Afonso report about transformation of the study group of Ateliê Fidalga, in which they assumed the role of mediating dialogue and fostering exchanges in a horizontal process of mutual learning in art, for the Fidalga Project, composed of 4 collective workshops, three exhibition rooms, and an artistic residency program with the objective of hosting experimental exhibitions and works developed by resident artists and invited artists.

Keywords: Art; Atelier Fidalga; Fidalga Project; Artistic residence; Collaboration between artists.. 


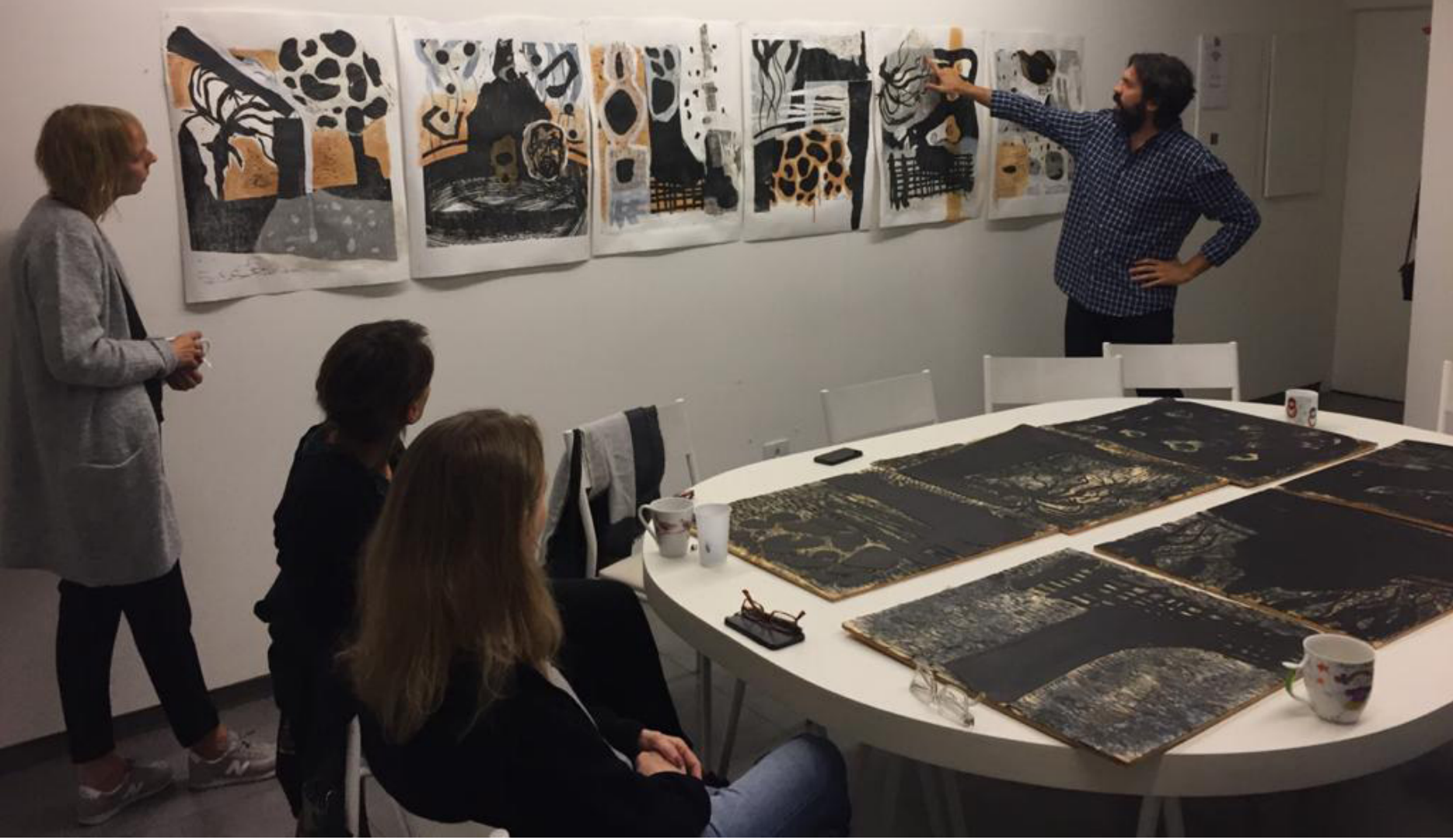

Figura 2. Encontro realizado pelo Ateliê Fidalga. Foto do acervo dos autores. volvimento das poéticas pessoais, estimular o diálogo e fomentar trocas, num processo horizontal de aprendizado mútuo.

Temos o comprometimento de respeitar as individualidades e aprender com elas.

Se a arte é um exercício de liberdade, o que tentamos fazer é estimular a criação e dar aos artistas instrumentos para que essa criação seja contextualizada, fomentar o pensamento e a reflexão crítica sobre as questões de nosso tempo.

Nosso papel é mediar o diálogo e fomentar trocas, num processo horizontal de aprendizado mútuo.
Chegamos a receber semanalmente 60 artistas, divididos em quatro grupos de 15. Atualmente temos cerca de 40 participantes que se reúnem semanalmente.

Os artistas apresentam seus projetos, expõem suas incertezas, dúvidas, compartilham suas experiências e percebem no outro um pouco de si. Esse espelhamento de si pelo outro é um dos caminhos possíveis para o diálogo.

Em 2012, o Ateliê Fidalga ganhou uma nova dimensão fruto de um amadurecimento do trabalho e necessidade de expansão: com a mudança para um novo espaço, transformamos o 

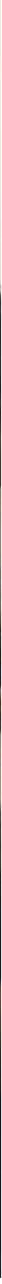

antigo local de nosso ateliê no Projeto Fidalga, composto de 4 ateliês coletivos, três salas expositivas, e um programa de residência artística. Um local sem fins lucrativos, com o objetivo de abrigar exposições experimentais e trabalhos desenvolvidos pelos artistas residentes e artistas convidados.

As exposições, palestras, workshops e a residência artística são realizadas num sistema de colaboração entre os artistas integrantes dos encontros, dos artistas que tem seus ateliês no projeto, nós e nossa equipe composta de 6 pessoas.
O trabalho é possível devido a rede de artistas colaboradores e parceiros do projeto num ambiente de trocas de experiências, num processo informal e orgânico de aprendizado que geram novos projetos, encontros e sinergia.

As parcerias entre os artistas dos encontros e os visitantes residentes acontecem de diferentes formas como por exemplo: empréstimo de materiais e equipamentos, acompanhamento em espaços de arte ou lugares pela cidade, traduções, registros fotográficos das exposições, passeios para outras cidades, , visitas a ateliês, almoços, jantares, ou seja, atividades cotidia-
Figura 3. Encontro realizado pelo Ateliê Fidalga. Foto do acervo dos autores. 

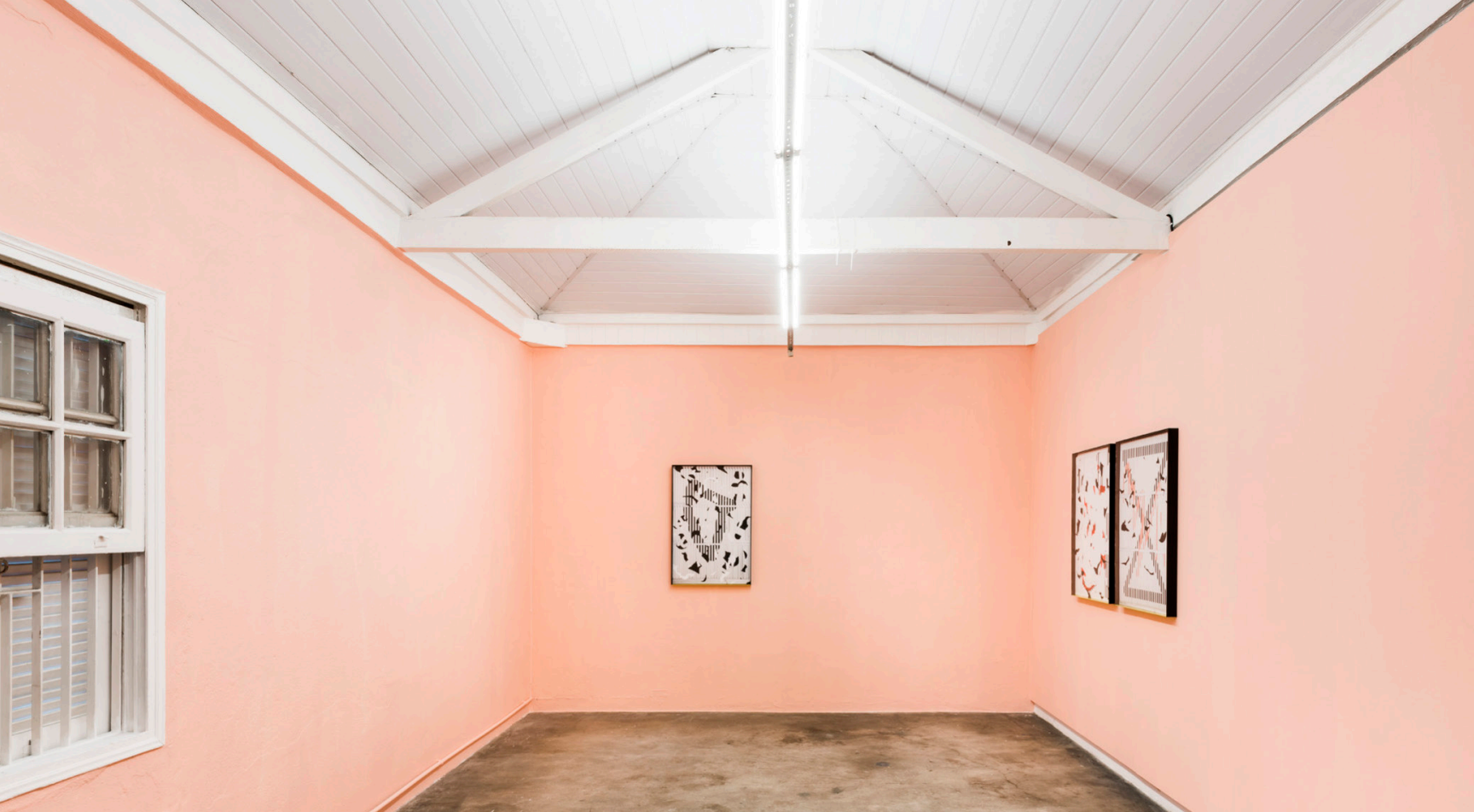
Projeto Macunaíma, IBAC/Funarte, Rio de Janeiro, RJ. 2000 - Locust Projects, Miami, EUA. 2003 - Auto-Retratos, Galeria Doque Arte Contemporânea, Barcelona, Espanha; Galeria Fernando Padilla, Madri, Espanha. 2005 - Pinturas de Luz, Casa dos Dias d’Água, Lisboa, Portugal. 2006 - A Imagem, Galeria Manoel Macedo, Belo Horizonte, MG; Albano Afonso - Foto Arte 2005, Espaço Ecco, Brasília, DF. Participou de grande número de exposições coletivas no Brasil e no exterior, destacando-se as seguintes: 1991 - 23 Salão de Arte Contemporânea, Museu de Arte da Pampulha, Belo Horizonte, MG. 1993 - Prêmio Gunther de Pintura, Museu de Arte Contemporânea, Universidade de São Paulo, SP. 1994 - 22 Salão de Arte Contemporânea de Santo André, Paço Municipal, Santo André, SP - Prêmio aquisição. 1994, 95 e 97 - Salão Paranaense, Museu de Arte Contemporânea do Paraná, Curitiba, PR. 1999 - A Casa Triângulo no Marp, Museu de Arte de Ribeirão Preto, Ribeirão Preto, SP. 2005 - Off Side, The Hugh Lane Gallery, Dublin, Irlanda. 2006 - Geração da Virada 10+1: os anos recentes da arte brasileira, Instituto Tomie Ohtake, São Paulo; Constelações Afectivas I e Constelações Afectivas II, Galeria Graça Brandão, Lisboa, Portugal. 2006; É Hoje - Coleção Gilberto Chateaubriand, Espaço Cultural Santander, Porto Alegre, RS; 5ème Biennale Internationale de la Photagraphie et des Arts Visuels de Liège, Bélgica; Um Século de Arte Brasileira - Coleção Gilberto Chateaubriand, Pinacoteca do Estado, São Paulo, SP. 